\title{
REMINISCÊNCIAS DO PASSADO: O TRABALHO EM SITUAÇÃO ANÁLOGA À ESCRAVIDÃO E A LUTA PELA LIBERDADE
}

\author{
Antônio Pedro de Mélo Netto* \\ Mariana Loureiro Gama**
}

\begin{abstract}
RESUMO
O trabalho é uma atividade humana capaz de gerar riqueza, melhoria na condição de vida e promover o desenvolvimento. Todavia a exploração do trabalho pode ferir a dignidade humana e a liberdade individual, como é o caso de reduzir pessoas a condição análoga à escravidão, diante da afronta aos direitos fundamentais e está associada a prática de outros crimes, como o tráfico de pessoas e a organização criminosa. Deste modo, busca-se através da pesquisa histórico-descritivo, quando ao objeto, e em relação ao procedimento técnico, revisão bibliográfica e documental, analisar a questão do trabalho forçado no Brasil na atualidade.
\end{abstract}

PALAVRAS-CHAVE: Direito do Trabalho. Redução à condição análoga a Escravo. Liberdade. Direitos Fundamentais. Organização Criminosa.

\section{REMINISCENCES OF THE PAST: WORK IN A SITUATION ANALOGUE TO SLAVERY AND FIGHT FOR FREEDOM}

\begin{abstract}
Work is a human activity capable of generating wealth, improving the condition of life and promoting development. However, exploitation of labor can harm human dignity and individual freedom, such as reducing people to a condition analogous to slavery, in face of the violation of fundamental rights and associated with the practice of other crimes, such as trafficking in persons and Organization. In this way, we search through the historical-descriptive research, when to the object, and in relation to the technical procedure, bibliographical and documentary revision, analyze the question of forced labor in Brazil at the present time.
\end{abstract}

KEYWORDS: Labor Law. Reduction of Slave-like condition. Freedom. Fundamental Rights. Criminal Organization.

\footnotetext{
* Professor do curso de Direito da Faculdade Reinaldo Ramos (CesRei) e da Faculdade Maurício de Nassau (FMN), unidade Campina Grande. Mestre em Direito e Desenvolvimento de Mercado Sustentável pela UNIPE, pesquisador CNPQ Grupo de Estudos em Sociologia da Propriedade Intelectual, linha Filosofia do Direito, Ética e Estética da Propriedade Intelectual, a partir 2015. Especialização em Direito Público pela Faculdade Estácio do Recife (2014), advogado militante desde 2010 e graduado pela Universidade Estadual da Paraíba (UEPB) em 2009. Tem experiência na área de direito, com ênfase em Direito Civil, Econômico, Consumidor e Processo do Trabalho.

E-mail: antoniopedronetto@gmail.com

**: Professora das Faculdades Integradas e Patos (FIP). Mestre em Direito e Desenvolvimento de Mercado Sustentável pelo Centro Universitário de João Pessoa (UNIPÊ). Especialização em Direito Administrativo e Gestão Pública, pelo Centro Universitário de João Pessoa (UNIPE). Especialização em Direito Material e Processual do Trabalho pela ESMAT-13. Graduada pela Universidade Estadual da Paraíba (UEPB). E-mail: marianaloureiro_@hotmail.com
} 


\section{INTRODUÇÃO}

O trabalho é elemento essencial da forma de vida humana. É em decorrência dele e sobre seu fundamento que se sustenta toda a estrutura da sociedade ocidental. No entanto, não é toda forma de trabalho que pode ser considerada justa, digna e condizente com a condição humana. Durante a história da humanidade, ocorreram diversos períodos em que foi considerada legal e legítima a coisificação e exploração do homem pelo homem, pois o exercício do trabalho físico era considerado indigno.

Com base nessa crença, é que o ocidente legitimou a escravidão durante anos. Utilizando o negro, traficado da África para o Novo Mundo, para ser explorado nas plantações de monoculturas, garantindo um baixo custo de produção e uma alta rentabilidade aos seus proprietários.

O desenvolvimento do capitalismo ocasionou a necessidade da formação de um novo mercado consumidor que somado ao fortalecimento de direitos, da dignidade da pessoa humana e da liberdade, bem como aos movimentos de resistência a escravidão, terminou por extinguir legalmente a escravidão no Brasil em 1888. Contudo, a Lei Áurea não foi suficiente para acabar com a redução do trabalhador à condições análogas a escravo.

Após vários anos sem informações sobre o assunto, o tema voltou a ser discutido devido a repetidas denúncias de trabalhadores em condições indignas. Estas ocasionaram a implantação de grupos e programas estatais com o fito de extinguir tais práticas. Define-se como problema deste artigo a discussão das políticas públicas para extinção do trabalho forçado na defesa do trabalho digno e livre. Tendo em vista a ligação entre o crescimento econômico e o trabalho, objetiva-se esclarecer e identificar o conceito de trabalho forçado, as ações repressivas a sua prática, a proteção ao trabalhador e as condições que o tornam vulnerável a esta situação. Metodologicamente, utilizou-se de pesquisa histórico-descritiva, em relação aos seus objetivos; quanto ao procedimento técnico, a pesquisa é bibliográfica e documental.

A questão acerca do trabalho análogo à escravidão passa a ser atual quando levamos em consideração as pressões do mercado pela continuidade do baixo custo de 
produção e aumento de produtividade, situação agravada com o aumento da concorrência com produtos estrangeiros de baixo custo, como os chineses. Vale salientar que estas condições são vistas em todas as áreas, não só na rural, deixando de ser um ranço da escravidão e ganhando novos contornos.

\section{DAS ORGANIZAÇÕES CRIMINOSAS E DO TRÁFICO DE PESSOAS: AS ESTRUTURAS CRIMINOSAS QUE LEVAM O TRABALHADOR A CONDIÇÃO ANÁLOGA À ESCRAVIDÃo}

O labor está intimamente relacionado à vida humana, assim como a sua exploração, independentemente do sistema econômico e da época. Após a Revolução Industrial, intensas lutas são iniciadas na busca por garantir maior proteção e melhores condições de trabalho. Influenciadas pelas teorias marxistas, na alta exploração do trabalhador, nas precárias condições de trabalho toda a regulação do trabalho foi alterada. Entretanto, os avanços do passado não impedem retrocessos no presente, bem como a proibição legal sem fiscalização não extingue práticas nefastas ainda resistentes no Brasil.

\subsection{DO TRABALHO E DA CONDIÇÃO ANÁLOGA À ESCRAVIDÃO}

O trabalho sempre foi um elemento importante da vida humana, na construção de uma vida digna. Tanto assim o é que Hannah Arendt (2010) cunhou o conceito vida activa, na obra Condição Humana, por entender que a atividade humana é composta pela união de três elementos: o labor, o trabalho e a ação. O labor concerne ao próprio processo biológico humano (nascer, crescer, morrer e alimentar-se), sendo-o a própria vida, que termina por privá-lo da liberdade, pois pressupõe necessidade. Já o trabalho tem caráter cultural, correspondendo ao processo artificial de produção de objetos úteis e duráveis para facilitar e estabilizar a vida humana, ou seja, implica mundanidade. E a ação corresponde à pluralidade, pois a condição humana tem relação com a política e a diversidade, sendo o espaço da interpessoalidade e o ambiente da intersubjetividade.

Deste modo, observa-se que o trabalho está vinculado à própria existência do homem, sendo ele responsável pela melhoria nas condições de vida, mas nem sempre foi assim. O trabalho já foi considerado indigno por algumas sociedades e, por isso, deveria ser executado por subalternos. Assim, durante a antiguidade clássica, os gregos 
e os romanos tinham escravos para exercer trabalhos domésticos e rurais, geralmente presos de guerra ou reduzidos a esta condição por não terem pago suas dívidas. Apesar de comumente se falar na escravidão ocidental, até a Idade Média ela ocorria em todo o globo com maior ou menor intensidade a depender da região, entretanto sem vinculação à cor da pele, à etnia ou origem.

Na Idade Moderna, com o objetivo de garantir uma grande lucratividade e uma produção de baixo custo no novo mundo, para suprir o mercado europeu, iniciou-se a escravidão do negro para trabalhar nas plantações de monoculturas nas Américas, tendo em vista que o europeu não aceitaria condições de trabalho tão precárias. Ademais, o povo português, colonizador do Brasil, apresentava uma rejeição natural ao trabalho, em contraposição aos países do norte da Europa e os demais países centrais que, após a Revolução Protestante, passaram a propagar a ideia da dignidade através do trabalho. Neste sentido, o sociólogo Sérgio Buarque de Holanda (2014, p. 43), em relação aos povos ibéricos, afirma que:

Um fato que não se pode deixar de tomar em consideração no exame da psicologia desses povos é a invencível repulsa que sempre lhes inspirou toda moral fundada no culto ao trabalho. Sua atitude normal é precisamente o inverso da que, em teoria, corresponde ao sistema do artesanato medieval, onde se encare o trabalho físico, denegrindo o lucro, o "lucro torpe". Só muito recentemente, como o prestígio maior das instituições dos povos do Norte, é que essa ética do trabalho chegou a conquistar algum terreno entre eles. Mas as resistências que encontrou e ainda encontra têm sido tão vivas e perseverantes, que é lícito duvidar de seu êxito completo.

Deste modo, percebe-se que seja pela questão econômica, seja pelo aspecto sociológico, o Brasil encontrou razões para atrasar, ao máximo, o fim da escravidão, que só ocorreu em 13 de maio de 1888, com a sanção da Lei Áurea pela Princesa Isabel, após grande pressão internacional. Porém, o fim legal da escravidão e o interstício de mais 120 anos, não foram suficientes para extingui-la de fato da sociedade.

Vale salientar que não se pode dizer que existe escravidão moderna, pois o meio de produção escravista foi extinto no século XIX, mas, sim, pessoas que trabalham em situações tão degradantes que são assemelhadas às impostas àqueles que viveram em escravidão. Todavia, para evitar a repetição constante do termo, usa-se a expressão 
trabalho escravo ou trabalho forçado neste artigo como sinônimo de trabalho em condições análogas à escravidão.

Após tantos anos da abolição, solidificou-se a crença de que o trabalho escravo estava extinto no território nacional. Fato não comprovado, sendo essa crença fundada apenas na ausência de denúncias sobre o tema e na lenta conscientização de que o trabalhador rural é detentor de direitos. Assim, pelas razões expostas, a criminalização da conduta de reduzir alguém a condição análoga a de escravo ocorreu apenas em 1940, através do art. 149 do Código Penal. Assim, entre os anos de 1888 a 1940, o Estado brasileiro tolerou a propriedade de uma pessoa por outra, apesar não mais reconhecer através da legislação essa relação.

Neste processo lento de dignificação do trabalhador rural, Nogueira (2013, p. 221) relata que "a obrigação de garantir os direitos trabalhistas só foi editada em 1963, com o Estatuto do Trabalhador Rural, [...] vinte anos depois da Consolidação das Leis do Trabalho, [...] uma vez que a igualdade jurídica só veio com a Constituição Federal de 1988." Assim, Nogueira (2013, p. 221) afirma que

\begin{abstract}
Apenas em 1971, foi feita a primeira denúncia pública de trabalho escravo nos estados do Mato Grosso, Pará e Goiás, através da Carta Pastoral: "Uma igreja da Amazônia em Conflito com o Latifúndio e a Marginalização Social", pelo Bispo D. Pedro Casaldáliga. [...] foi o primeiro texto público a tratar do tema e expor a realidade dos trabalhadores submetidos ao trabalho escravo.
\end{abstract}

Porém, apenas em 2003, para evitar uma condenação, o Brasil aceitou o Termo de solução amistosa, em que assumiu uma série de compromissos para o combate ao trabalho escravo. Nesse mesmo período, foram criadas a Comissão Nacional de Erradicação do Trabalho Escravo - CONATRAE - e organizações estaduais, vinculadas a Secretaria de Direitos Humanos, o Ministério Público do Trabalho e o Ministério do Trabalho, Emprego e Previdência Social, com o fito de reprimir e extinguir de vez o trabalho escravo no Brasil.

O Código Penal (1940), no art. 149, define tal crime como

Reduzir alguém a condição análoga à de escravo, quer submetendo-o a trabalhos forçados ou a jornada exaustiva, quer sujeitando-o a condições degradantes de trabalho, quer restringindo, por qualquer meio, sua locomoção em razão de dívida contraída com o empregador ou preposto. 
Deste modo, compreende-se que o tipo penal visa proteger a liberdade individual, sob aspecto o ético-social, protegendo a dignidade pessoal e das relações de trabalho, não se exigindo que exista uma verdadeira escravidão no modelo antigo. Ademais, a legislação vigente não restringe sua aplicação apenas ao trabalhador rural, mas também abarca os trabalhadores urbanos que estejam submetidos a trabalhos forçados ou a jornadas exaustivas, mesmo que não forçadas. Esses trabalhadores são submetidos a condições degradantes de trabalho, restringindo sua saída da propriedade agrícola ou condicionando-o ao pagamento dos débitos aos quais era responsável ou forçando o trabalhador a serviços pesados e extraordinário, sob a coerção de um intermediário do empregador ou do tomador de serviços, que frequentemente empregava violência ou ameaça de violência. Diante de tais constatações, é possível analisar que não é apenas a ausência de liberdade que faz um trabalhador escravo, mas sim a falta de dignidade.

Estas situações geralmente estão vinculadas a outros ilícitos, como o tráfico de pessoas e a exploração sexual, bem como o sweating system ${ }^{1}$, prática moderna e urbana de exploração de trabalho, onde pequenas oficinas servem de local de prestação de serviços nas periferias dos centros urbanos, para empresas intermediárias terceirizadas de grandes marcas de moda, sob rigoroso controle de qualidade da mercadoria produzida ou no setor de construção civil.

Apesar da passagem do tempo, a fundamentação econômica continua sendo o principal fator para a existência do trabalho forçado, pois a parca remuneração e a diminuição das condições de trabalho auxiliam no aumento da competitividade e no crescimento econômico.

Para Schmidt (2013, p. 281)

Em alguns aspectos, a escravidão contemporânea é mais cruel do que a antiga escravidão. O escravo-bem custava importância considerável, o que demandava cuidado do senhor, enquanto que o trabalhador escravizado hoje é "descartável", pois o custo da mão de obra é muitas vezes apenas equivalente ao transporte de acordo com Ricardo Rezende Figueira, a escravidão contemporânea (rural) envolve quatro

\footnotetext{
${ }^{1}$ Segundo o site Repórter Brasil, Sweating System é o sistema em que locais de trabalho se confundem com residências, envolve condições extremas de opressão e salários miseráveis.
} 
aspectos fundamentais: nela a pessoa é tratada como se fosse mercadoria; há, mesmo que temporariamente, uma totalidade de poder exercida sobre ela; a vítima é alguém de fora, "um estrangeiro"; os donos de escravos temporários não têm criadouros de escravos.

Em caráter internacional, a Organização Internacional do Trabalho (OIT) publicou as Convenções no 29 (1930) e $n^{\circ} 105$ (1957), ambas ratificadas pelo Brasil em 25/04/1957 e 18/06/1965, respectivamente, nas quais é definido trabalho forçado (Convenção $n^{\circ} 29$ ) e as formas de sua imposição (Convenção $\left.n^{\circ} 105\right)$ :

Art. 2 - 1. Para os fins da presente convenção, a expressão 'trabalho forçado ou obrigatório' designará todo trabalho ou serviço exigido de um indivíduo sob ameaça de qualquer penalidade e para o qual ele não se ofereceu de espontânea vontade.

Art. 1 - Qualquer Membro da Organização Internacional do Trabalho que ratifique a presente convenção se compromete a suprimir o trabalho forçado ou obrigatório, e a não recorrer ao mesmo sob forma alguma:

a) como medida de coerção, ou de educação política ou como sanção dirigida a pessoas que tenham ou exprimam certas opiniões políticas, ou manifestem sua oposição ideológica à ordem política, social ou econômica estabelecida;

b) como método de mobilização e de utilização da mão-de-obra para fins de desenvolvimento econômico;

c) como medida de disciplina de trabalho;

d) como punição por participação em greves;

e) como medida de discriminação racial, social, nacional ou religiosa.

O trabalho análogo à escravidão utiliza-se muitas vezes do tráfico de pessoas, através de organizações criminosas, haja vista que fora do seu território, as pessoas sentem-se mais vulneráveis, como menor capacidade de resistência, tendo em vista a ausência de familiares, amigos e organizações estatais as quais possam se auxiliar para conseguir sua liberdade frente às condições indignas de trabalho. A situação do trabalhador sujeito a tais condições agrava-se quando ele é estrangeiro, como acontece nos sweating system, pois geralmente o trabalhador está na condição de imigrante ilegal, sem documentos de identificação e sem compreensão suficiente da língua. Portanto, percebe-se que onde há trabalho escravo, poderá está configurado também o tráfico de pessoas.

\subsection{DA ORGANIZAÇÃO CRIMINOSA E DO TRÁFICO DE PESSOAS}

A luta contra o crime organizado no aspecto jurídico surgiu ainda no início do século passado, na tentativa de impedir o tráfico de pessoas, especialmente o das 
mulheres brancas. Nogueira apresenta a sequência normativa internacional na busca por coibir o tráfico de pessoas por organizações criminosas:

Os três primeiros se deram no âmbito da Liga das Nações, enquanto os últimos foram criados já no contexto da Organização das Nações Unidas (ONU):

- Acordo para a Repressão do Tráfico de Mulheres Brancas, 1904 (Decreto n. 5.591/1905);

- Convenção Internacional para a Repressão do Tráfico de Mulheres Brancas, 1910 (Decreto n. 16.572/1924);

- Convenção Internacional para a Repressão do Tráfico de Mulheres e Crianças, 1921 (Decreto n. 28.812/1930); Protocolo de Emenda da Convenção para a Repressão do Tráfico de Mulheres e de Crianças, 1921 (Decreto n. 37.176/1955);

- Convenção para a Repressão do Tráfico de Mulheres Maiores, 1933 (Decreto n. 37.176/1955);

- Convenção para a Repressão do Tráfico de Pessoas e do Lenocínio, 1949 (Decreto n. 46.981/1959).

O "Protocolo de Palermo" (Protocolo Adicional à Convenção das Nações Unidas contra o Crime Organizado Transnacional Relativo à Prevenção, Repressão e Punição do Tráfico de Pessoas, em Especial Mulheres e Crianças, 2000) foi ratificado pelo Brasil em 2004, por meio do Decreto n. 5.017, de 12 de março de 2004. Em seu art. $3^{\circ}$, dá a definição consensuada sobre o que é tráfico de pessoas, e reconhece todas as suas formas abrindo novas perspectivas para o debate, por tratar o tráfico de pessoas como exploração, mercantilização de seres humanos, por não se restringir à questão da prostituição, por priorizar a atenção às vítimas e por ser um instrumento de direitos humanos. (NOGUEIRA et al, 2013, p. 225 - 226)

Após o atentado terrorista de 11 de setembro de 2001, nos EUA, a preocupação com as organizações de pessoas para prática de crimes aumentou, causando diversas mudanças legislativas sobre o tema no mundo. Estas alterações basearam-se principalmente na Convenção de Palermo (Convenção das Nações Unidas Contra o Crime Organizado), adotada em Nova York em 15 de novembro de 2000, que definiu Organização Criminosa no seu art. $2^{\mathrm{a}}$, a, como sendo o

grupo estruturado de três ou mais pessoas, existente há algum tempo e atuando concertadamente com o propósito de cometer uma ou mais infrações graves ou enunciadas na presente Convenção, com a intenção de obter, direta ou indiretamente, um benefício econômico ou outro benefício material. (ONU, Convenção de Palermo, art. 2a a) 
No Brasil, discute-se o tema desde a década de 80, quando foi criada uma comissão especial sobre o crime organizado que culminou com a promulgação da Lei 9.034/95 com o objetivo de combater o crime organizado e o tráfico de drogas. Como fruto das reflexões legais locais e internacionais, foi sancionada a Lei 12.850/13, fechando o tipo penal de organização criminosa e prevendo a punição inclusive àqueles que promoverem, constituírem, integrarem ou financiarem-na. $\mathrm{O}$ art. $1^{\circ}$ da Lei citada dispõe:

Art. $1^{\circ}$ Esta Lei define organização criminosa e dispõe sobre a investigação criminal, os meios de obtenção da prova, infrações penais correlatas e o procedimento criminal a ser aplicado.

$\S 1^{\circ}$ Considera-se organização criminosa a associação de 4 (quatro) ou mais pessoas estruturalmente ordenada e caracterizada pela divisão de tarefas, ainda que informalmente, com objetivo de obter, direta ou indiretamente, vantagem de qualquer natureza, mediante a prática de infrações penais cujas penas máximas sejam superiores a 4 (quatro) anos, ou que sejam de caráter transnacional. (BRASIL, Lei 12.850/13)

Houve uma evolução na legislação que definiu com mais exatidão os contornos do tipo organização criminosa, separando-a mais claramente da associação criminosa (art. 288 do CP) e do concurso de pessoas (art. 29 CP). O elemento do tipo que destacase é a necessidade de quatro ou mais pessoas em uma estrutura organizada e caracterizada pela divisão de tarefas. Tais termos indicam que a organização precisa ter um líder e subordinados que executem tarefas específicas, definidas, assemelhando-as com as estruturas empresariais, mas com elas não se confundindo, e de caráter não temporário, deve estender-se no tempo, ser permanente, mas não necessariamente perpétua, na prática delitiva, que pode ser crimes ou contravenções.

Todavia, estas organizações nem sempre estão afastadas do Estado, ao contrário, algumas vezes, estão umbilicalmente ligadas a ele, como afirma Hassemer:

a criminalidade organizada não é apenas uma organização bem-feita, não é somente uma organização internacional, mas é, em última análise, a corrupção do Legislativo, da Magistratura, do Ministério Público, da polícia, ou seja, a paralisação estatal no combate à criminalidade. Nós conseguimos vencer a máfia russa, a máfia italiana, a máfia chinesa, mas não conseguimos vencer uma Justiça que esteja paralisada pela criminalidade organizada, pela corrupção. (HASSEMER,1993, p. 85). 
Ao fato do seio das organizações criminosas muitas vezes estarem profundamente ligadas ao Estado, o que é sinal de uma crise do direito, termina por traduzir-se numa crise da democracia, pois, segundo Bitencourt (2014, p. 17), "termina por traduzir uma crise do princípio da legalidade, da sujeição dos poderes públicos à lei, na qual se fundam tanto a soberania popular quanto o paradigma do Estado de Direito".

Deste modo, percebe-se que apesar das organizações criminosas permearem a história real e literária, após a adoção da democracia pela maioria dos países ocidentais, seu caráter revolucionário foi basicamente extinto diante da descriminalização da política, da liberdade de pensamento e de reunião que ascenderam à condição de garantias fundamentais constitucionais. Porém, estas organizações subsistem em todo o globo, promovendo a prática de delitos econômicos, de tráfico de pessoas, armas, drogas e do terrorismo.

Assim, este crime não encontra barreiras sociais, ao revés, seus agentes muitas vezes são autoridades, pessoas públicas, de grande capacidade de renda ou patrimônio, que insatisfeitos com os ritos legais, organizam-se, dividindo tarefas, de forma permanente, para o próprio favorecimento ilícito, invertendo a lógica do Estado, subordinando-o aos ditames da organização.

Desta forma, não é surpreendente que organizações criminosas promovam o tráfico de pessoas para trabalhar em situação análoga à escravidão em favor de empresas mundialmente famosas, como o notório caso da marca de roupas espanhola Zara. Assim, para Nogueira et. al. (2013), a aproximação entre o Direito do Trabalho e o Penal é essencial para garantir a proteção dos direitos humanos através da incorporação dos avanços empreendidos por cada uma, conforme determinou o Protocolo de Palermo (2000) ao incluir na definição de tráfico de pessoas elementos típicos do trabalho escravo como o recrutamento, transporte, alojamento, coação, uso da força, engano, vulnerabilidade e outros.

No tráfico de pessoas utiliza-se de intermediários ou agenciadores, vulgarmente conhecidos como gatos ou coiotes, de obreiros que intermedeiam a relação trabalhista com o objetivo de exonerar o empregador real de qualquer responsabilidade, em desacordo com o art. 58-A, $\S 2^{\circ}$ da CLT, o qual determina que o empregador deve arcar 
com os custos do transporte do trabalhador para o local de trabalho. Ao utilizar o agenciador, o empregador transfere esse ônus para o empregado, que não tem recurso financeiro para quitá-lo, gerando uma dívida que prende o trabalhador ao empregador (que assume a dívida em seu lugar).

\section{O ESTADO COMO TUTOR DA LIBERDADE E DAS CONDIÇÕES MÍNIMAS DO TRABALHO DIGNO}

Independente da formação educacional, das características culturais e do tempo, a liberdade sempre esteve intimamente relacionada ao ser humano. Cada pessoa do mundo, independente de todas as características personalíssimas que a torna única, é capaz de entender o que significa esse direito, independente de seu aspecto formal filosófico. Neste sentido, Melo \& Figueiredo (2016) afirmam

Responsável por grandes diásporas, quedas e ascensões de impérios e religiões, a liberdade sempre foi fundamento dos maiores movimentos na história humana. Ansiada por cada indivíduo e por todos os povos através dos tempos, foi base de muitas rebeliões, guerras e revoluções, desde as romanas (Revolta de Espártaco) até as dos dias atuais, com a Primavera Árabe (2011).

Assim, percebe-se que, mesmo antes dos filósofos debruçarem-se sobre este preceito e sentimento humano, todo indivíduo tem a compreensão do que a liberdade é ou representa, independente da sua tutela pelo Estado e dos variados conceitos a ela conferidos. Em razão do direito à liberdade ser considerado inerente ao ser humano, independente de positivação, ela é considerada um direito jusnaturalista, pois surge com a própria existência do ser humano, independente de nacionalidade, língua e etnia.

Assim, apesar do seu aspecto intrínseco ao ser o humano, historicamente a liberdade está sempre sob a ameaça de ser suplantada em função de interesses políticos, econômicos ou sociais. Em função destes constantes ataques, nasceu o mote republicano que afirma que "o preço da liberdade é a eterna vigilância", cuja autoria é indicada a Aldous Huxley, Thomas Jefferson, Patrick Henry e John Philpot Curran, ambos ferrenhos defensores das liberdades individuais e do cidadão em face do Estado e do grande capital.

Diante deste enredo, com o objetivo de garantir maior estabilidade a este direito, constantemente vilipendiado e principalmente em decorrência dos conflitos sociais 
vividos durante o século XVIII, que culminou com a Revolução Francesa, foi positivado na Declaração Universal dos Direitos do Homem (1948), em seu art. $4^{\mathrm{o}}$ :

A liberdade consiste em poder fazer tudo que não prejudique o próximo. Assim, o exercício dos direitos naturais de cada homem não tem por limites senão aqueles que asseguram aos outros membros da sociedade o gozo dos mesmos direitos. Estes limites apenas podem ser determinados pela lei.

Porém, a liberdade, segundo estabelecida na Declaração dos Direitos do Homem e do Cidadão, engloba os aspectos políticos, civis e econômicos. Segundo o Dicionário de Política de Norberto Bobbio (1998, p.709), “a liberdade política é uma subcategoria da liberdade social e normalmente se refere à liberdade dos cidadãos ou das associações em relação ao Governo", compreendida como a ausência de restrições para que o indivíduo participe da vida em sociedade, participando de reuniões e ações sociais.

Já as liberdades civis são aquelas que visam garantir ou preservar o indivíduo do poder discricionário do Estado, desdobrando-se em direito à privacidade, liberdade de consciência, religiosa, associação, expressão etc. Por fim, as liberdades econômicas são aquelas vinculadas mais intrinsecamente ao direito de propriedade, pois visam garantir ao cidadão o direito de decidir como dispor dos seus recursos econômicos, tornando os agentes econômicos livres da coerção de pessoas públicas ou privadas, através do trabalho e patrimônio. (MÉLO \& FIGUEIREDO, 2016)

Vale ainda salientar que estas liberdades estão todas associadas, sendo impossível a desagregação das atividades civis, econômicas e políticas. Friedman (1988, p. 17) afirma que

Geralmente se acredita que política e economia constituem territórios separados, apresentando pouquíssimas interrelações; que a liberdade individual é um problema político e o bem-estar material, um problema econômico; e que qualquer tipo de organização política pode ser combinado com qualquer tipo de organização econômica. [...] A tese deste capítulo é que um tal ponto de vista é puramente ilusório; que existe uma relação íntima entre economia e política; que somente determinadas combinações de organizações econômicas e políticas são possíveis; e que, em particular, uma sociedade socialista não pode também ser democrática, no sentido de garantir a liberdade individual.

Ainda no mesmo sentido, o autor afirma que

A organização econômica desempenha um papel duplo na promoção de uma sociedade livre. De um lado, a liberdade econômica é parte da 
liberdade entendida em sentido mais amplo e, portanto, um fim em si própria. Em segundo lugar, a liberdade econômica é também um instrumento indispensável para a obtenção da liberdade política.

Deste modo, percebe-se que a classificação das liberdades dá-se apenas para efeitos didáticos. Ao contrário, em razão dos seus âmbitos estarem todos entrelaçados, o impacto das alterações das liberdades econômicas gera impactos instantâneos nos campos cíveis e políticos, ou de qualquer uma delas nas demais. Neste sentido, Amartya Sen (2013, p. 25) afirma que

os encadeamentos entre diferentes formas de liberdade são empíricos e causais, e não constitutivos e compositivos. Por exemplo, há fortes indícios de que as liberdades econômicas e políticas se reforçam mutuamente, em vez de serem contrárias umas às outras.

No mesmo ínterim, a Declaração Universal dos Direitos Humanos (1948) ratifica o compromisso internacional com a liberdade, dentre elas a do trabalho, e com a dignidade humana, prevendo no art. $4^{\circ}$ que "ninguém será mantido em escravatura ou em servidão; a escravatura e o trato dos escravos, sob todas as formas, são proibidos”.

Em razão do enredo histórico da promulgação da Constituição Federal de 1988, a sociedade brasileira, ciente do seu dever de vigilância, buscando evitar novas restrições à liberdade como as impostas durante a Ditadura Militar (1964-1985), protegeu o direito à liberdade, no art. $5^{\circ}$, no título dos Direitos e Garantias Fundamentais, e no art. $60, \S 4^{\circ}$, elevando-a a cláusula pétrea, que permitem alteração constitucional. Além disso, até pelo

aspecto analítico da Constituição, reiterou e especificou sua proteção diversas vezes por todo o texto magno. Vejamos:

Art. $5^{\circ}$ Todos são iguais perante a lei, sem distinção de qualquer natureza, garantindo-se aos brasileiros e aos estrangeiros residentes no País a inviolabilidade do direito à vida, à liberdade, à igualdade, à segurança e à propriedade, nos termos seguintes:

II - ninguém será obrigado a fazer ou deixar de fazer alguma coisa senão em virtude de lei;

Ao debruçar-se sobre a Carta Magna, José Afonso da Silva (2006, p. 234-235), diferencia a liberdade em cinco grupos diferentes, previamente afirmando que a 
liberdade que interessa ao direito é a liberdade positiva (liberdade de fazer, liberdade de atuar), apresentando-as como

(1) liberdade da pessoa física (liberdade de locomoção, de circulação);

(2) liberdade de pensamento, com todas as suas liberdades (opinião, religião, informação, artística, comunicação do conhecimento);

(3) liberdade de expressão coletiva em suas várias formas (de reunião, de associação);

(4) liberdade de ação profissional (livre escolha e de exercício de trabalho, ofício e profissão).

(5) liberdade de conteúdo econômico e social (liberdade econômica, livre iniciativa, liberdade de comércio, liberdade ou autonomia contratual, liberdade de ensino e liberdade de trabalho), de que trataremos entre os direitos econômicos e sociais, porque não integram o campo dos direitos individuais, mas o daqueles.

Destarte, independente da diversidade de categorizações, percebe-se que a liberdade de trabalho e econômica estão interligadas e gerando um dos maiores impactos na sociedade, e, por isso, é protegida pela Constituição de diversas maneiras. Por exemplo, a Carta Magna no art. $1^{\circ}$, IV, prevê como fundamento da República os valores sociais do trabalho e da livre iniciativa. Reiterando a importância desses preceitos, nos art. 170, afirmando que a ordem econômica é fundada neles.

A Constituição apresenta ainda dois princípios norteadores das atividades públicas e privadas, que visam garantir a liberdade econômica: o Princípio da Livre Concorrência e da Livre Iniciativa. Contanto, estes são ponderados pelos valores sociais do trabalho que impedem os abusos a classe operaria com justificativas econômicas, como o ganho de produtividade ou maior crescimento econômico, garantindo a preservação da dignidade nas relações de trabalho.

Protege-se a liberdade e a dignidade de trabalho e do trabalhador para garantir o exercício do direito constitucional à liberdade, tendo em vista que o cidadão jamais será realmente livre, caso esteja subjugado a tal situação de vulnerabilidade, ou miserabilidade, ao passo que só tenha sua força de trabalho para vender para garantir sua sobrevivência ou dos seus. Assim, para garantir que o trabalhador não seja subordinado a condição análoga à escravidão, é preciso compreender que para exercer a liberdade de contratar, segundo o princípio da autonomia da vontade, é preciso que ele tenha as condições mínimas de independência para negociar as cláusulas contratuais 
básicas, como o salário, que deve ser suficiente para proporcionar ao homem e seus dependentes o que eles necessitam para sobreviver.

A ausência dessas condições, ou a vida em constante necessidade, obriga o trabalhador a aceitar condições de trabalho indignas, incompatíveis com a condição humana, nos aspectos Arentidianos, sendo impossível exigir o cumprimento do contrato de trabalho, segundo os ditames do Princípio da Obrigatoriedade Contratual, por não se reconhecer a paridade entre as partes, ou mesmo, a liberdade em não contratar sob pena de condenar a si e a sua família à fome e a morte. Tal situação é claramente percebida pelo legislador que incluiu após aguerridas lutas o princípio da hipossuficiência do trabalhador com base na subordinação econômica.

Desta forma, uma das maiores preocupações daqueles que atuam na libertação dos cativeiros é garantir os trabalhadores não sejam novamente aliciados a trabalhos forçados por ausência de oportunidade de labor onde residem ou por ausência de condições para sustentar a si e as suas famílias. Diante desse quadro, a Lei 10.608/02, autorizou a concessão do benefício do Seguro-Desemprego ao trabalhador resgatado, com o objetivo de dar uma assistência financeira temporária. Além desse suporte financeiro, o trabalhador será encaminhado pelo Ministério do Trabalho e Emprego, para qualificação profissional e recolocação no mercado de trabalho.

Em outra via, com o intuito de coibir a prática da utilização de trabalho forçado, a Emenda Constitucional n ${ }^{\circ}$ 81, de 2014, acrescentou o art. 234 na Constituição Federal, determinando que as propriedades rurais e urbanas de qualquer região do país onde for localizada a exploração de trabalho escravo serão expropriadas e destinadas à reforma agrária e a programas de habitação popular, sem direito à indenização ao proprietário. Ainda foi criada a Lista Suja, na qual é inserido o nome dos empregadores envolvidos na prática do trabalho escravo, que proíbe o financiamento público às pessoas físicas ou jurídicas condenadas administrativamente por exploração de trabalho escravo.

\section{CONSIDERAÇÕES FINAIS}

O capitalismo sempre buscou o menor custo de produção para que assim pudesse gerar os maiores lucros. Para tanto, na ausência da ética, em desrespeito a direitos fundamentais e porque não dizer basilares da norma positivada, tendo em vista sua origem jusnaturalista, como a liberdade e a dignidade da pessoa humana, o mercado 
incentivou a escravização do homem pelo homem com o objetivo de garantir baixo custo e aumento de produtividade.

Infelizmente toda essa ordem foi protegida por normas jurídicas rígidas, permitindo que a escravidão perdurasse mais de dois séculos no Brasil. Com a sanção da Lei Áurea em 1888, o Brasil acreditou que tivesse superado à imposição de trabalhos forçados em seu território. Todavia, a redução do trabalhador a condição análoga à escravidão só foi tipificada como crime em 1940, e a igualdade de direitos entre trabalhadores urbanos e rurais foi reconhecida em 1988, com a promulgação da Constituição de 1988.

Em desacordo com as normas legais, o tráfico de pessoas continuou a existir no Brasil. A publicação da Lei Áurea não foi suficiente para extirpar do modelo econômico a exploração degradante do trabalho, principalmente no campo. Assim, em meados da década de 1970, começaram a surgir as primeiras denúncias de trabalhos forçados. Em razão das representações em diversos organismos internacionais, o Brasil instituiu programas de erradicação de trabalho forçado, utilizando para tanto a fiscalização dos auditores fiscais do trabalho em parceria com o Ministério Público do Trabalho para persecução criminal e aplicação de indenização por violação de direitos metaindividuais daqueles que reduziram o trabalhador a condição análoga a escravo.

Para a prática deste crime, o criminoso se utiliza da condição de miserabilidade do trabalhador, enganando-o com ofertas de trabalho em locais distantes da sua moradia. Em condição de pobreza extrema, sem educação formal, sem ter como suprir as necessidades da sua família, o obreiro aceita a proposta, que foi feita através de um intermediador, ou atravessador, e desloca-se para longe da sua família e amigos, aumentando sua condição de vulnerabilidade.

Como se pode notar, para reduzi-lo a condição análoga à escravo, comumente utiliza-se do deslocamento geográfico, que mesmo dentro do mesmo território nacional, pode caracterizar o tráfico de pessoas, tão reprimido desde o início século XX. Tal atividade, geralmente é executada por um grupo de pessoas, organizadas em estrutura assemelhada à empresarial, na qual existe um chefe e subordinados que executam ordens, não efêmera, o que configura a prática de crime organizado. 
Deste modo, percebe-se que a imposição em trabalhos forçados é uma prática que envolve a execução de outros crimes, como o tráfico de pessoas e a organização criminosa, os trabalhadores, sujeitos passivos do crime, geralmente encontram-se marginalizados social e economicamente. Para inibir essa prática, o Estado atua no desmantelamento dos cativeiros e, de forma preventiva, mitigar de forma emergencial sua condição de miserabilidade, autorizou a concessão do seguro-desemprego para estes trabalhadores, bem como determinou a utilização de programas de inserção no mercado de trabalho.

Infelizmente, a atuação do Estado não vem sendo suficiente para a extinção definitiva dessa prática. Com os avanços econômicos da última década, o Brasil começou a atrair mais imigrantes estrangeiros dos países vizinhos, muitas vezes ilegais, que trabalham em condições sub-humanas em regiões metropolitanas, em fábricas de roupas ou na construção civil. Para estes, a situação é ainda mais grave, pois envolve o desconhecimento da língua e a condição de imigrante ilegal, que gera um receio de procurar auxílio junto aos órgãos estatais de proteção ao trabalhador.

Aos que são libertos dessa condição, é reconhecido todos os direitos trabalhistas através de Reclamações Trabalhistas em face do empregador. Infelizmente, todas essas medidas ainda não foram suficientes para acabar com esta prática que merece atenção da sociedade e do Estado, devido ao aumento da concorrência com os produtos estrangeiros, principalmente chineses, de baixo valor. Deste modo, a superação dessa forma de exploração do trabalhador exige mais fiscalização e punições mais duras, inclusive com a perda da propriedade, já prevista em lei, mas não aplicada como o devido.

\section{REFERÊNCIAS}

ARENDT, Hannah. A Condição Humana. Trad. Roberto Raposo. Rev. Adriano Correia. $11^{\mathrm{a}}$. ed. Rio de Janeiro: Forense Universitária, 2010. pp. 8-25.

ÁVILA, Humberto. Teoria dos Princípios: da definição à aplicação dos princípios jurídicos. 4 ed. São Paulo: Malheiros Editores Ltda, 2005. 
BIGNAMI, Renato. Sweating system, trabalho escravo contemporâneo no setor têxtil. Portal Repórter Brasil. Disponível em: <http://reporterbrasil.org.br/2011/12/sweatingsystemtrabalho-escravo-contemporaneo-no-setor-textil/> Acesso 08 de jan. 2017.

BITENCOURT, Cezar Roberto. Comentários à Lei de Organização Criminosa: Lei 12.850/13. São Paulo: Saraiva, 2014.

BOBBIO, Noberto; MATTEUCCI, Nicola; PASQUINO, Gianfranco. Dicionário de Política. 11ed. Brasilia: Editora UNB, 1998.

BRASIL. Constituição (1988). Constituição da República Federativa do Brasil. Brasília, DF: Senado Federal.

Decreto $\mathbf{N}^{\circ}$ 2.848. Código Penal. Disponível em:

<http://www.planalto.gov.br/ccivil_03/decreto-lei/Del2848compilado.htm>. Acesso em 27 de dez 2016.

Decreto $N^{0}$ 5.015. Promulga a Convenção das Nações Unidas contra o Crime Organizado Transnacional. Disponível em:

<http://www.planalto.gov.br/ccivil_03/_Ato2004-2006/2004/Decreto/D5015.htm>. Acesso em 07 de jan 2016.

Decreto Lei $n^{0}$ 5.452: Consolidação das Leis do Trabalho. Disponível em: <http://www.planalto.gov.br/ccivil/Decreto-Lei/Del5452.htm>. Acesso em 07 de jan 2016.

Lei n. ${ }^{0} 10.608$ de 20 de dezembro de 2002. Altera a Lei no 7.998, de 11 de janeiro de 1990, para assegurar o pagamento de seguro-desemprego ao trabalhador resgatado da condição análoga à de escravo. Disponível em:

<ttps://www.planalto.gov.br/ccivil_03/Leis/2002/L10608.htm>. Acesso em: 12 jan. 2017.

Lei n. ${ }^{\circ} 12.850$ de 02 de agosto de 2013. Define organização criminosa e dispõe sobre a investigação criminal, os meios de obtenção da prova, infrações penais correlatas e o procedimento criminal; altera o Decreto-Lei no 2.848, de 7 de dezembro de 1940 (Código Penal); revoga a Lei no 9.034, de 3 de maio de 1995; e dá outras providências. Disponível em: <https://www.planalto.gov.br/ccivil_03/_ato20112014/2013/lei/112850.htm>. Acesso em: 25 dez. 2016.

FARIA, Heraldo Felipe de. Livre concorrência na concepção de Adam Smith. Revista Direitos Fundamentais \& Democracia. n. 8, julho2010. p. 287-300. Disponível em: <http://vlex.com/vid/livre-na-adam-smith-417957962>. Acesso em 13 de jan 2017.

FRIEDMAN, Milton. Capitalismo e Liberdade. São Paulo: Nova Cultural, 1988.

GOMES, Luiz Flávio. Definição de crime organizado e a Convenção de Palermo.

Disponível em: <http://www.lfg.com.br>. Acesso em: 03 de dez. 2016. 
GRECO FILHO, Vicente. Comentários à Lei de Organização Criminosa. São Paulo: Saraiva, 2014.

HASSEMER. Winfried. Três temas de direito penal. Porto Alegre: Publicações Fundação Escola Superior do Ministério Público, 1993.

HOLANDA, Sérgio Buarque de. Raízes do Brasil. 27 ed. São Paulo: Companhia das Letras, 2014.

MELO NETTO, Antonio Pedro \& FIGUEIREDO, Ediliane Leite Lopes. In: DIREITO, ECONOMIA E DESENVOLVIMENTO SUSTENTÁVEL II. LIBERDADE E DESENVOLVIMENTO SUSTENTÁVEL: uma análise acerca do impacto da liberdade econômica na promoção do desenvolvimento. Curitiba: Congresso Nacional do CONPEDI, 2017.

NOGUEIRA, Christiane, et. al. TRÁFICO DE PESSOAS E TRABALHO ESCRAVO: Além da interposição de conceitos. Revista do Ministério Público do Trabalho, No 46, set. de 2013.

NOLETO. Eliézer de Queiroz. Trabalho escravo X Trabalho decente. 2009. Disponível em: http://www2.camara.leg.br/documentosepesquisa/publicacoes/estnottec/areas-da-conle/tema8/2004-7324.pdf > Acesso em 20 de jan. 2017.

OIT. CONVENÇÃO 29. Disponível em: <http://www.oitbrasil.org.br/node/449> Acesso 05 de jan. de 2017.

OIT. CONVENÇÃO 105. Disponível em: <http://www.oitbrasil.org.br/node/469 convenção 105> Acesso 05 de jan. de 2017.

ONU. Convenção das Nações Unidas contra o Crime Organizado Transnacional. Disponível em <https://www.unodc.org/lpo-brazil/pt/crime/marco-legal.html> Acesso 03 de dez. 2016.

ONU. Declaração Universal dos Direitos do Homem, 1948. Acesso em 03 de dez. 2016.

Relatório Brundtland, da Comissão Mundial sobre Meio Ambiente e Desenvolvimento da ONU. Disponível em: <www.un.org> Acesso em 14/02/2016.

PINTO, Cláudia M. B. Costa. O princípio constitucional da libre concorrência e o proceso de globalização. Revita Bonijuris. N. 548. julho 2009. p. 5-8. Disponível em: <http://vlex.com/vid/principio-constitucional-livre-ncia-76312426>. Acesso em $14 \mathrm{de}$ jan. de 2017.

SCAR, ROGER. Liberdades Civis X Liberdades econômicas. Portal Libertarianismo. Disponível em : <http://www.libertarianismo.org/index.php/artigos/liberdades-civisxliberdades-economicas/>. Acessado em: 12 de jan. 2017. 
SCHMIDT, Martha Halfeld Furtado de Mendonça. O trabalho forçado contemporâneo -Comentários às Convenções Fundamentais ns. 29 e 105 da Organização Internacional do Trabalho - $O$ texto e o contexto. Disponível em < http://vlex.com/vid/trabalho-neofundamentais-508921558> Acesso em 10 de jan. 2017.

SEN, Amartya. Desenvolvimento como liberdade. São Paulo: Companhia das Letras, 2010.

SILVA, José Afonso. Curso de Direito Constitucional Positivo. 25ª ed. São Paulo: Ed. Malheiros, 2006.

SHIKIDA, Cláudio. O preço da liberdade é a eterna vigilância. Acadêmicos de Milton Friedman. 11 de agosto de 2016. Disponível em:

$<$ http://www.academicosdemiltonfriedman.com/\#!O-pre\%C3\%A7o-da-liberdade$\%$ C3\%A9-a-eterna-vigil\%C3\%A2ncia/jasvv/57aca4690cf2d58e4d035a66>. Acesso em: 20 de ago de 2016.

SOUZA, José Fernando Vidal. Os direitos difusos e coletivos: o meio ambiente. In: LEMOS FILHO, A. et al. Sociologia do Direito. 3.ed. Campinas: Alínea, 2008.

UNIVERSIDADE DE SÃO PAULO. Biblioteca Virtual de Direitos Humanos. DECALRAÇÃO DOS DIREITOS DO HOMEM E DO CIDADÃO (1789).

Disponível em: <http://www.direitoshumanos.usp.br/index.php/Documentos-anteriores$\% \mathrm{C} 3 \% \mathrm{~A} 0-$ cria\%C3\% A7\% $3 \%$ A3o-da-Sociedade-das-

Na\%C3\%A7\%C3\%B5esat\%C3\%A9-1919/declaracao-de-direitos-do-homem-e-docidadao-1789.html> .Acesso em 10 de jan de 2017.

UNIVERSIDADE DE SÃO PAULO. Biblioteca Virtual de Direitos Humanos. DECALRAÇÃO UNIVERSAL DOS DIREITOS HUMANOS (1948). Disponível em: <http://www.direitoshumanos.usp.br/index.php/Declara\%C3\%A7\%C3\%A3oUniversal-dosDireitos-Humanos/declaracao-universal-dos-direitos-humanos.html > Acesso em 10 de jan de 2017. 